ORIGINAL ARTICLE

\title{
United States pedestrian fatality rates by vehicle type
}

\section{J Paulozzi}

Injury Prevention 2005;11:232-236. doi: 10.1136/ip.2005.008284

\begin{abstract}
Objective: To describe the relation between motor vehicle type and the risk of fatally injuring a pedestrian. Design: The risk of killing a pedestrian was measured as the number of pedestrian fatalities per billion miles of vehicle travel by each vehicle type in the US in 2002 as reported by the National Highway Traffic Safety Administration's Fatality Analysis Reporting System.

Interventions: None.

Main outcome measures: Rates for each vehicle type by sex, age, and rural/urban roadway type and rate comparisons using relative risks (RR) and $95 \%$ confidence intervals $(\mathrm{Cls})$.

Results: Passenger cars and light trucks (vans, pickups, and sport utility vehicles) accounted for $46.1 \%$ and $39.1 \%$, respectively, of the 4875 deaths, with the remainder split among motorcycles, buses, and heavy trucks. Compared with cars, the RR of killing a pedestrian per vehicle mile was $7.97195 \% \mathrm{Cl} 6.33$ to 10.04 ) for buses; $1.93(95 \% \mathrm{Cl} 1.30$ to 2.86$)$ for motorcycles; 1.45 (95\% Cl 1.37 to 1.55$)$ for light trucks, and $0.96(95 \% \mathrm{Cl} 0.79$ to 1.18$)$ for heavy trucks. Compared with cars, buses were 11.85 times $(95 \% \mathrm{Cl}$ 6.07 to 23.12$)$ and motorcycles were 3.77 times $(95 \% \mathrm{Cl} 1.40$ to 10.20$)$ more likely per mile to kill children 0-14 years old. Buses were 16.70 times ( $95 \% \mathrm{Cl} 7.30$ to 38.19 ) more likely to kill adults age 85 or older than were cars. The risk of killing a pedestrian per vehicle mile traveled in an urban area was 1.57 times $(95 \% \mathrm{Cl} 1.47$ to 1.67$)$ the risk in a rural area.

Conclusions: Outcomes reflect the ways in which a vehicle's characteristics (mass, front end design, and visibility) and its degree of interaction with pedestrians affect its risk per mile. Modifications in vehicle design might reduce pedestrian injury. The greatest impact on overall US pedestrian mortality will result from reducing the risk from the light truck category.
\end{abstract}

Correspondence to: Dr L J Paulozzi, 4770 Buford Highway, NE, Mailstop K-63, Atlanta, GA 30341, USA; Lbp4@cdc.gov

Accepted 29 March 2005
$\mathrm{T}$ he standard public health approach to pedestrian injuries is that used for most injuries - the study of the victims or "hosts". This standard approach has revealed that risk factors for pedestrian injury include male sex, advanced age, urban residence, and alcohol consumption. ${ }^{12}$ Public health and traffic safety literature, however, has focused very little on the characteristics of the "agents", the motor vehicles that strike the pedestrians. Therefore, relatively little is known about the risks posed to pedestrians by different vehicles or types of drivers.

Almost half of all pedestrian fatalities in the United States are associated with passenger cars; about $40 \%$ are associated with light trucks, a category that includes vans, pickups, and sport utility vehicles (SUVs). Only $5 \%$ of pedestrian fatalities are associated with large trucks, and $2 \%$ are associated with buses. ${ }^{3}$ However, these percentages largely reflect the relative numbers of different vehicle types. One way to adjust for the unequal distribution of vehicle types in the motor vehicle fleet is to calculate the risk of pedestrian death per vehicle mile traveled by each vehicle type.

This study combined information on pedestrian fatalities (categorized by vehicle type involved) with the vehicle miles traveled by each vehicle type to calculate fatality rates. Rates were stratified by the pedestrian's sex and age and the roadway location (rural versus urban). The study attempted to determine whether risk varied by vehicle type and whether risk was modified by victim sex, victim age, or rural/urban occurrence.

\section{METHODS}

Data on pedestrian deaths in 2002 were provided by the National Highway Traffic Safety Administration's (NHTSA) Fatality Analysis Reporting System (FARS). FARS data come primarily from police accident reports. These reports include information on the body type of vehicles involved in fatal crashes, the victim's sex and age, and whether the crash occurred on a rural or urban roadway. FARS captures all injury deaths occurring within 30 days of a crash that involve motor vehicles traveling on public roadways. This study categorizes "pedestrians" as both those walking in and using equipment or conveyances in the roadway (for example, wheelchairs, skateboards, roller blades, or cherry pickers). ${ }^{4}$

Information on vehicle miles traveled on public roadways by vehicle type and roadway type came from the US Department of Transportation Federal Highway Administration's (FHWA) 2002 highway statistics. ${ }^{5}$ Vehicle miles were determined by traffic count samples and did not include off-road motor vehicle travel. When reporting to the FARS system, police apply the FHWA road classification scheme to record the roadway type (rural or urban). "Urban" roadways are defined as those in towns or cities with populations of 5000 or more.

FARS and the FHWA classify vehicle body types in the same way. "Passenger cars" include sedans, hatchbacks, and station wagons. The "light truck" category includes vans, pickups, SUVs, and similar vehicles. The "heavy truck" category includes straight trucks with six or more tires not towing a trailer. The "combination truck" category includes trucks with six or more tires towing trailers. The "motorcycle" category includes mopeds, scooters, off-road motorcycles, and other two and three wheeled motorized vehicles. The "buses" category includes school buses, intercity buses, and transit buses. The "other/unknown" category includes all-terrain vehicles, snowmobiles, farm equipment, construction equipment, and other special use vehicles. The vehicle

Abbreviations: $\mathrm{Cl}$, confidence interval; FARS, Fatality Analysis Reporting System; FHWA, Federal Highway Association; NHTS, National Household Travel Survey; NHTSA, National Highway Traffic Safety Administration; RR, relative risk; SUV, sport utility vehicle. 
Table 1 Number of pedestrian deaths by vehicle type, sex, age, and roadway type (rural/urban), United States, 2002

\begin{tabular}{|c|c|c|c|c|c|c|c|c|}
\hline Characteristic & Car* & Motorcycle & Bus & $\begin{array}{l}\text { Light } \\
\text { truckt }\end{array}$ & $\begin{array}{l}\text { Heavy } \\
\text { truck }\end{array}$ & $\begin{array}{l}\text { Combination } \\
\text { truck } \ddagger\end{array}$ & $\begin{array}{l}\text { Other/ } \\
\text { unknown }\end{array}$ & Total \\
\hline \multicolumn{9}{|l|}{ Sex } \\
\hline Male & 1518 & 15 & 39 & 1285 & 68 & 126 & 267 & 3318 \\
\hline Female & 729 & 10 & 35 & 619 & 31 & 35 & 96 & 1555 \\
\hline Unknown & 1 & 0 & 0 & 0 & 0 & 0 & 1 & 2 \\
\hline \multicolumn{9}{|l|}{ Age (years) } \\
\hline $0-14$ & 184 & 4 & 9 & 173 & 6 & 8 & 18 & 402 \\
\hline $15-24$ & 261 & 4 & 4 & 238 & 11 & 23 & 44 & 585 \\
\hline $25-44$ & 661 & 5 & 17 & 574 & 25 & 63 & 113 & 1458 \\
\hline $45-64$ & 603 & 7 & 21 & 483 & 28 & 48 & 115 & 1305 \\
\hline $65-84$ & 423 & 5 & 16 & 358 & 25 & 16 & 56 & 899 \\
\hline $85+$ & 87 & 0 & 6 & 62 & 3 & 2 & 8 & 168 \\
\hline Unknown & 29 & 0 & 1 & 16 & 1 & 1 & 10 & 58 \\
\hline \multicolumn{9}{|l|}{ Roadway } \\
\hline Rural & 610 & 9 & 11 & 589 & 31 & 96 & 82 & 1428 \\
\hline Urban & 1630 & 16 & 62 & 1306 & 68 & 64 & 280 & 3426 \\
\hline Unknown & 8 & 0 & 1 & 9 & 0 & 1 & 2 & 21 \\
\hline Total number & 2248 & 25 & 74 & 1904 & 99 & 161 & 364 & 4875 \\
\hline Total (\%) & 46.1 & 0.5 & 1.5 & 39.1 & 2.0 & 3.3 & 7.5 & 100.0 \\
\hline
\end{tabular}

type may be unknown in a hit and run fatality. If two or more vehicles struck the pedestrian, the vehicle causing the most significant injury was coded. If that vehicle could not be determined, the vehicle striking the pedestrian first was coded.

Fatality rates were calculated as pedestrian deaths per billion miles of vehicle travel. Rates could not be calculated for the "other/unknown" vehicle type category because there is no measure of miles traveled by such vehicles. Rates were compared using relative risks (RR) with passenger cars as the referent; the $95 \%$ confidence intervals (CI) for RRs were calculated using Epi-Info 2002. ${ }^{6}$

\section{RESULTS}

A total of 4875 pedestrian fatalities occurred in 2002 (table 1). Passenger cars, SUVs, vans, and pickups combined were involved in $85.2 \%$ of these deaths. Motorcycles and buses were involved in fewer than 100 deaths each. Vehicle type was unknown for $7.5 \%$. FARS reported the sex and age of the pedestrian and the type of roadway for over $98 \%$ of deaths.

Overall, there were 1.71 pedestrian deaths per billion vehicle miles traveled (table 2). Buses-although associated with fewer deaths than passenger cars-were almost eight times more likely to be involved in pedestrian fatalities per mile traveled. Motorcycles and light trucks also showed a significantly increased relative risk compared with passenger cars.

Motor vehicles were twice as likely to kill male pedestrians than female pedestrians per vehicle mile. The male-female rate difference was most pronounced for combination trucks. Buses showed the same rates for males as females. However, when compared with cars, buses were significantly more likely to kill females, and combination trucks were significantly less likely.

Motorcycles were significantly more likely than cars per vehicle mile to kill children $0-14$ years old (table 3 ), whereas

\begin{tabular}{|c|c|c|c|}
\hline Vehicle type & Male & Female & Total \\
\hline \multicolumn{4}{|l|}{$\overline{C a{ }^{*}}$} \\
\hline Rate & 0.92 & 0.44 & 1.36 \\
\hline $\operatorname{RR}(95 \% \mathrm{Cl})$ & 1 (referent) & 1 (referent) & 1 (referent) \\
\hline \multicolumn{4}{|l|}{ Motorcycle } \\
\hline Rate & 1.57 & 1.05 & 2.62 \\
\hline $\operatorname{RR}(95 \% \mathrm{Cl})$ & $1.72(1.03-2.85)$ & $2.38(1.28-4.44)$ & $1.93(1.30-2.86)$ \\
\hline \multicolumn{4}{|l|}{ Bus } \\
\hline Rate & 5.69 & 5.11 & 10.80 \\
\hline $\operatorname{RR}(95 \% \mathrm{Cl})$ & $6.22(4.53-8.54)$ & $11.63(8.29-16.31)$ & $7.97(6.33-10.04)$ \\
\hline \multicolumn{4}{|l|}{ Light truck† } \\
\hline Rate & 1.33 & 0.64 & 1.97 \\
\hline $\operatorname{RR}(95 \% \mathrm{Cl})$ & $1.45(1.35-1.57)$ & $1.46(1.31-1.62)$ & $1.45(1.37-1.55)$ \\
\hline \multicolumn{4}{|l|}{ Heavy truck } \\
\hline Rate & 0.90 & 0.41 & 1.30 \\
\hline $\operatorname{RR}(95 \% \mathrm{Cl})$ & $0.98(0.77-1.25)$ & $0.93(0.65-1.33)$ & $0.96(0.79-1.18)$ \\
\hline \multicolumn{4}{|c|}{ Combination truck } \\
\hline Rate & 0.91 & 0.25 & 1.16 \\
\hline $\operatorname{RR}(95 \% \mathrm{Cl})$ & $0.99(0.83-1.19)$ & $0.57(0.41-0.81)$ & $0.86(0.73-1.01)$ \\
\hline \multicolumn{4}{|l|}{ Total } \\
\hline Rate & 1.16 & 0.54 & 1.71 \\
\hline
\end{tabular}


Table 3 Relative risk of pedestrian mortality by vehicle type and age group, United States, 2002

\begin{tabular}{|c|c|c|c|c|c|c|}
\hline \multirow[b]{2}{*}{ Vehicle type } & \multicolumn{6}{|l|}{ Age group (years) } \\
\hline & $0-14$ & $15-24$ & $25-44$ & $45-64$ & $65-84$ & $85+$ \\
\hline \multicolumn{7}{|l|}{ Car* } \\
\hline $\operatorname{RR}(95 \% \mathrm{Cl})$ & 1 (referent) & 1 (referent) & 1 (referent) & 1 (referent) & 1 (referent) & 1 (referent) \\
\hline \multicolumn{7}{|l|}{ Motorcycle } \\
\hline $\operatorname{RR}(95 \% \mathrm{CI})$ & $3.77(1.40-10.20)$ & $2.66(0.99-7.14)$ & $1.31(0.54-3.17)$ & $2.02(0.96-4.24)$ & $2.05(0.85-4.96)$ & $0.00(0.00-9.66)$ \\
\hline \multicolumn{7}{|l|}{ Bus } \\
\hline $\operatorname{RR}(95 \% \mathrm{Cl})$ & $11.85(6.07-23.12)$ & 3.71 (1.38-9.96) & 6.23 (3.85-10.07) & $8.43(5.46-13.02)$ & $9.16(5.56-15.08)$ & $16.70(7.30-38.19)$ \\
\hline \multicolumn{7}{|l|}{ Light truck† } \\
\hline $\operatorname{RR}(95 \% \mathrm{Cl})$ & 1.61 (1.31-1.99) & $1.56(1.31-1.87)$ & 1.49 (1.33-1.67) & $1.37(1.22-1.55)$ & $1.45(1.26-1.67)$ & $1.22(0.88-1.69)$ \\
\hline \multicolumn{7}{|l|}{ Heavy truck } \\
\hline $\operatorname{RR}(95 \% \mathrm{Cl})$ & $0.71(0.32-1.61)$ & $0.92(0.50-1.68)$ & $0.83(0.55-1.23)$ & 1.01 (0.69-1.48) & $1.29(0.86-1.93)$ & $0.75(0.24-2.38)$ \\
\hline \multicolumn{7}{|l|}{ Combination truck $\ddagger$} \\
\hline $\operatorname{RR}(95 \% \mathrm{Cl})$ & $0.52(0.26-1.06)$ & $1.05(0.69-1.61)$ & $1.14(0.88-1.48)$ & $0.95(0.71-1.28)$ & $0.45(0.27-0.75)$ & $0.27(0.07-1.12)$ \\
\hline
\end{tabular}

buses showed relative risks above 10 for both children and the elderly aged 85 years and older. Light trucks were significantly more likely than cars per mile to kill a pedestrian of any age group.

The rate of death per vehicle mile traveled in an urban area was 1.57 times (95\% CI 1.47 to 1.67 ) the rural rate (table 4 ). The urban rate exceeded the rural rate for every vehicle type. When compared with the risk per mile of a car killing a pedestrian, the relative risks for other vehicle types were comparable in rural and urban areas, with the exception of buses, which are much more likely to kill a pedestrian in an urban than in a rural area. Almost all the excess risk for buses overall, therefore, derives from urban buses.

\section{DISCUSSION}

This study calculated the risk of pedestrian fatalities for different types of motor vehicles using miles traveled as a measure of exposure. Marked differences were found between measuring the risk of such a fatality in deaths per mile traveled and measuring the risk from the number or proportion of deaths associated with different vehicle types. For example, motorcycles and buses were involved in relatively few pedestrian deaths, but were much more likely than passenger cars to be involved in a pedestrian fatality for every billion miles of travel. The study also confirmed that the growing population of vans, pickups, and SUVs is mile-formile more likely to be involved in pedestrian fatalities than passenger cars. These risks varied appreciably by the sex and age of the victim and the rural/urban location of the roadway.

The risk of a driver killing a pedestrian in this study was 1.7 per billion miles of travel. In comparison, FARS data show that the overall motor vehicle fatality rate in the US in 2002 was 15.0 per billion vehicle miles traveled. ${ }^{3}$ Omitting the 4875 pedestrian deaths and the 662 bicyclist deaths reported by NHTSA for 2002 results in a motor vehicle occupant fatality rate of 13.0 per billion miles of vehicle travel, indicating that a traveling motor vehicle is roughly 7.6 (13.0/1.7) times more likely to kill an occupant than to kill a pedestrian for every mile it travels.

However, the risk per mile that a driver has of killing a pedestrian depends greatly on what kind of vehicle he or she is driving. The greater risk while driving a bus has been noted previously. ${ }^{78}$ This is probably because buses need to operate in close proximity to pedestrians who have been or will be bus passengers as well because of the large mass of buses. In a few cases, it also may reflect features of bus design such as

\begin{tabular}{|c|c|c|c|}
\hline Vehicle type & Rural & Urban & Total \\
\hline \multicolumn{4}{|l|}{ Car* } \\
\hline Rate & 1.00 & 1.55 & 1.36 \\
\hline $\operatorname{RR}(95 \% \mathrm{Cl})$ & 1 (referent) & 1 (referent) & 1 (referent) \\
\hline \multicolumn{4}{|l|}{ Motorcycle } \\
\hline Rate & 2.02 & 3.13 & 2.62 \\
\hline $\operatorname{RR}(95 \% \mathrm{Cl})$ & $2.02(1.05-3.90)$ & $2.02(1.23-3.30)$ & $1.93(1.30-2.86)$ \\
\hline \multicolumn{4}{|l|}{ Bus } \\
\hline Rate & 2.79 & 21.36 & 10.80 \\
\hline $\operatorname{RR}(95 \% \mathrm{Cl})$ & $2.78(1.54-5.05)$ & $13.75(10.70-17.67)$ & $7.97(6.33-10.04)$ \\
\hline \multicolumn{4}{|l|}{ Light truck† } \\
\hline Rate & 1.53 & 2.25 & 1.97 \\
\hline $\operatorname{RR}(95 \% \mathrm{Cl})$ & $1.53(1.37-1.71)$ & $1.44(1.34-1.55)$ & $1.45(1.37-1.55)$ \\
\hline \multicolumn{4}{|l|}{ Heavy truck } \\
\hline Rate & 0.81 & 1.81 & 1.30 \\
\hline $\operatorname{RR}(95 \% \mathrm{Cl})$ & $0.81(0.56-1.16)$ & $1.16(0.91-1.48)$ & $0.96(0.79-1.18)$ \\
\hline \multicolumn{4}{|c|}{ Combination truck $\ddagger$} \\
\hline Rate & 1.10 & 1.25 & 1.16 \\
\hline $\operatorname{RR}(95 \% \mathrm{Cl})$ & $1.10(0.88-1.36)$ & $0.81(0.63-1.03)$ & $0.86(0.73-1.01)$ \\
\hline \multicolumn{4}{|l|}{ Total } \\
\hline Rate & 1.27 & 1.98 & 1.71 \\
\hline
\end{tabular}


pinch points that entrap clothing drawstrings, causing exiting passengers to be dragged beneath the bus. ${ }^{9}$ For buses, the relative risks of pedestrian fatalities are high, yet they are still in a sense underestimates because they do not include other deaths to which buses may have contributed, such as those of pedestrians struck by other vehicles while crossing the street in front of or behind a bus.

The increased risk that a motorcyclist has of killing a pedestrian has not been noted previously. One study of pedestrian deaths in 1977 found a lower risk for motorcycles than cars on a vehicle-mile basis. ${ }^{7}$ If there is in fact an increased risk from motorcycles, as this study suggests, it may reflect rider behaviors or the lower visibility of a motorcycle compared with a car.

The increased risk of killing a pedestrian experienced by drivers of light trucks (that is, vans, pickups, and SUVs) has been noted previously. Injury severity scores and case fatality rates are greater when a pedestrian is struck by a light truck than when struck by a car. ${ }^{10-13}$ A study conducted in Seattle revealed that vans and pickups accounted for a larger share of pedestrian fatalities than their share of registered motor vehicles. ${ }^{14}$ In a 2003 study, the NHTSA reported that the risk of fatal pedestrian collisions per million registered vehicles was about $20 \%$ greater for light trucks than for passenger cars and that the risk was greater for vans than for pickups or SUVs. ${ }^{15}$ The NHTSA study probably underestimated the risk associated with light trucks because, unlike this study, it was unable to adjust for the smaller average annual mileage of light trucks compared with cars. The increased risk associated with light trucks is attributed to several factors: their greater mass; greater vehicle speed of collision with pedestrians, and their front end design. This is a growing concern because US sales of new vehicles in the light truck category have approached $50 \%$ of all vehicle sales in recent years. ${ }^{10}$

The risk that drivers of heavy trucks and combination trucks have of killing a pedestrian are not statistically different from those associated with cars, despite the large mass of such trucks. This might suggest that such vehicles are less likely to be driven in areas congested with pedestrians and/or that these drivers are less likely to be intoxicated. FARS data indicate that drivers of large trucks are much less likely to be intoxicated in fatal crashes than are drivers of either cars or light trucks. ${ }^{3}$

The greater likelihood of killing a male than a female pedestrian for all vehicle types is not unexpected given that male sex is a well established risk factor in population based rates of pedestrian mortality. Riskier male behavior ${ }^{12}$ probably has a larger effect on these overall rates than does the tendency for women to walk more frequently than men. For example, the 2001 National Household Travel Survey (NHTS) indicates that females walk $10 \%$ more miles than men annually. ${ }^{16}$ For buses, however, male and female mortality rates are similar. This may in part reflect a greater use of buses by females; in fact, the 2001 NHTS shows that females travel $26 \%$ more miles by bus annually. ${ }^{16}$ In the study of clothing drawstring entrapment in school buses, 11 of 12 injured victims were girls, ${ }^{9}$ suggesting that the design of clothing for females may also be contributing to the risk.

These rate comparisons by sex ignore the fact that females outnumber men in the US population by $3.5 \%$. Correcting for the slightly greater female population would result in reducing the female rates per vehicle mile in table 2 by a few percent. This would only accentuate the male excess already noted in the crude rates.

The age stratification of risk by vehicle type in table 3 reveals differences at the extremes of age. Motorcycle and bus drivers are more likely than car drivers per mile to kill pedestrians aged $0-14$ years. Children probably have no more exposure to motorcycles than do young adults, but they may have difficulty seeing or being seen by approaching motorcycles. Children have greater exposure to buses than do adults. The NHTS indicates that children $0-14$ years of age travel more miles per person by bus than any other age group. Bus drivers are more likely than drivers of any other type of vehicle per mile to kill adults aged 85 years and older even though the NHTS indicates that this age group travels fewer miles per person by bus than any other age group. ${ }^{16}$ Combination trucks are less likely than cars to kill both children and elderly, perhaps because these age groups lack occupational exposures to such vehicles (for example, on loading docks or as road crews).

Most previous studies note that on a population basis, higher pedestrian fatality rates occur in urban areas. ${ }^{17}{ }^{18}$ The excess urban risk is usually attributed to greater numbers of both vehicles and pedestrians per square mile. In this study, the rural/urban rate difference for buses is nearly eightfoldperhaps because school and transit buses stop more often per mile in urban areas. In addition, much of rural bus travel occurs between cities on interstate highways, where pedestrians are usually prohibited.

The principal limitation of this study was that it calculated risk by vehicle type according to one component of exposure: the number of miles traveled by different vehicles. It could not consider the human component of exposure-how much, where, and when people walk. Therefore, the risk differences in this study may to some extent be explained by differences in various unmeasured aspects of walking behavior by sex, age, and rural/urban residence. Calculating risk according to characteristics such as miles walked per person, on the other hand, does not incorporate the vehicle exposure component. The two approaches are best seen as complementary.

Another limitation of the study is its inability to categorize vehicles by type in $7.5 \%$ of the fatalities; therefore, fatality rates are likely to be underestimates. Some of these other/ unknown vehicles were involved in hit and run crashesincidents that are more common in urban areas and less common when the victim is a female, a child, or a senior citizen. ${ }^{19}$ The number of such unknown vehicles, however, is not sufficient to markedly alter the risk differences noted here for these demographic variables.

Modification of the exterior of motor vehicles has been proposed as one cost effective strategy to reduce pedestrian injuries..$^{20}$ Potential modifications vary by vehicle type. For buses, risk might be reduced by improving the driver view of pedestrians, by removing pinch points for clothing drawstrings near doorways, or by padding the front end. ${ }^{21}$ This study suggests that such design modifications should be a higher priority for urban buses than for rural buses. The greater risk of pedestrian fatalities associated with motorcycles might be addressed by requiring daytime running lights. This has already been shown to reduce an automobile's risk of colliding with pedestrians, ${ }^{22}$ although the same has not yet been shown for motorcycles.

The greater mass of light trucks contributes to the severity of pedestrian injuries. However, it is difficult to change this characteristic of light trucks without affecting function. Risk might be reduced by making truck front ends less stiff and by lowering their point of impact with a pedestrian's body, thus reducing the likelihood of serious head and chest injuries. ${ }^{13} 23$

Given the small numbers in the motorcycle and bus categories, reducing risk per mile for these categories will not likely have much impact on overall pedestrian injury in the US. Risk reductions directed at buses would have a greater impact in less resourced countries where buses are involved in a large percentage of pedestrian injuries. ${ }^{24}$ Prevention measures in better resourced countries should focus on risk reductions from vans, pickups, and SUVs-especially because sales for these vehicles continue to grow. An increase in these 
vehicles on the roadways will likely contribute to an increased risk to both pedestrians and occupants of smaller passenger cars. ${ }^{25}$

\section{Key points}

- Cars and light trucks (vans, pickups, and SUVs) are responsible for $85.2 \%$ of pedestrian deaths in the United States, and heavy trucks, buses, and motorcycles are responsible for the remainder.

- Per mile of vehicle travel, buses kill eight times as many pedestrians as cars, and motorcycles kill twice as many.

- Per mile, buses are 12 times as likely and motorcycles are four times as likely as cars to kill pedestrians less than 15 years old.

- Per mile, light trucks are 1.45 times more likely to kill pedestrians than are cars.

- Vehicle characteristics such as mass, front end design, visibility, and degree of interaction with pedestrians probably determine their risk per mile.

\section{ACKNOWLEDGEMENTS}

The author appreciates the contribution of pedestrian fatality data from the FARS system by Tonja Lindsey of the National Highway Traffic Safety Administration and of technical information on vehicle type from Harshad Desai of the Federal Highway Administration.

Competing interests: none declared.

\section{REFERENCES}

1 National Highway Traffic Safety Administration. Anonymous. Pedestrians. Washington, DC: National Highway Traffic Safety Administration, 2004, DOT HS 809614 .

2 Wazana A, Krueger P, Raina $P$, et al. A review of risk factors for child pedestrian injuries: are they modifiable? Inj Prev 1997:3:295-304.

3 National Highway Traffic Safety Administration. Traffic Safety Facts 2002. Washington, DC: National Highway Traffic Safety Administration, 2004, DOT HS 809620 .
4 National Highway Traffic Safety Administration. Fatality Analysis Reporting System Coding Manual. Washington, DC: National Highway Traffic Safety Administration, 2004

5 Federal Highway Administration. Highway Statistics 2002. Washington, DC: Federal Highway Administration, 2003.

6 Centers for Disease Control. Epi-Info 2002. Atlanta, GA: Centers for Disease Control, 2002.

7 Wolfe AC, O'Day J. Pedestrian accidents in the U.S. HSRI. Res Rev 1982;12:1-16.

8 Komanoff C. Killed by automobile: death in the streets of New York City. New York City: Right of Way, 1999.

9 Drago D, Winston FK, Baker SP. Clothing drawstring entrapment in playground slides and school buses: contributing factors and potential interventions. Arch Pediatr Adolesc Med 1997;151:72-7.

10 Lefler DE, Gabler HC. The fatality and injury risk of light truck impacts with pedestrians in the United States. Accid Anal Prev 2004;36:295-304.

11 Ballesteros MF, Dischinger PC, Langenberg P. Pedestrian injuries and vehicle type in Maryland, 1995-1999. Accid Anal Prev 2004;36:73-81.

12 Roudsari BS, Mock CN, Kaufman R, et al. Pedestrian crashes: higher injury severity and mortality rate for light truck vehicles compared with passenger vehicles. Inj Prev 2004; 10:154-8.

13 Mizuno K, Kajzer J. Compatibility problems in frontal, side, single car collisions and car-to-pedestrian accidents in Japan. Accid Anal Prev 1999:31:381-91.

14 Rivara FP, Reay DT, Bergman AB. Analysis of fatal pedestrian injuries in King County, WA, and prospects for prevention. Public Health Rep 1989; 104:293-7.

15 Starnes $M$, Longthorne A. Child pedestrian fatality rates by striking vehicle body type: a comparison of passenger cars, sport utility vehicles, pickups, and vans. National Highway Traffic Safety Administration, 2003. DOT HS 809 640 (Traffic Safety Facts Research Note).

16 US Department of Transportation. 2001 National Household Travel Survey. Available at http://nhts.ornl.gov/2001 (accessed 15 August 2004).

17 Baker SP, O'Neill B, Karpf RS. The injury fact book. Lexington, Massachusetts: Lexington Books, 1984.

18 Mueller BA, Rivara FP, Bergman AB. Urban-rural location and the risk of dying in a pedestrian-vehicle collision. J Trauma 1988;28:91-4.

19 Solnick SJ, Hemenway D. The hit-and-run in fatal pedestrian accidents: victims, circumstances and drivers. Accid Anal Prev 1995;27:643-9.

20 Avenoso A, Beckmann J. The safety of vulnerable road users in the southern, eastern, and central European countries 2005. Available at www.etsc.be/ documents/Safety Vulnerable Road Users.pdf (accessed 10 March 2005).

21 Kajzer J, Yang JK, Mohan D. Safer bus fronts for pedestrian impact protection in bus-pedestrian accidents. International IRCOBI Conference on the Biomechanics of Impacts, 1992.

22 Koornstra M, Bijleveld F, Hagenzieker M, et al. The safety effects of daytime running lights. Institute for Road Safety Research, 1997. SWOV Report R-9736.

23 Chawla A, Mohan D, Sharma V, et al. Safer truck front design for pedestrian impacts. J Crash Prev Inj Cont 2000;2:33-43.

24 Peden $M$, Scurfield $R$, Sleet $D$, et al. World report on road traffic injury prevention. World report on road traffic injury prevention. Geneva: World Health Organization, 2004.

25 Acierno S, Kaufman R, Rivara FP, et al. Vehicle mismatch: injury patterns and severity. Acc Anal Prev 2004;36:761-72.

\section{Man unaware of $12 \mathrm{~cm}$ knife stuck in head}

\begin{abstract}
A 63-year-old Pole suffering headaches and lack of appetite was reportedly completely unaware that a $12 \mathrm{~cm}$ long knife blade stuck in his head was the source of his woes. Physicians in Bialystok were shocked to find the knife blade lodged in the cranium of the unidentified patient. The man suspects he sustained the injury after falling off a kitchen stool when he was drunk, but noticed no blood and had no major pain at the time. He later found the handle of his favourite knife but the blade had mysteriously vanished. Doctors simply pulled the blade out of the man's head without any complications, and the man was sent home with a clean bill of health after only two days in hospital.
\end{abstract}

Sydney Morning Herald, March 2005. Contributed by Ian Scott. 